\title{
Experimental Study on Liquid-solid Separation Process of Oxytetracycline Residue
}

\author{
Yin-ping CAI ${ }^{1, a,{ }^{*}}$, Yue-yun $\mathrm{Li}^{2, \mathrm{~b}}$, Yu-xin $\mathrm{Yu}^{1, \mathrm{c}}$, Meng WANG ${ }^{1, \mathrm{~d}}$ \\ ${ }^{1}$ Binzhou Polytechnic, Binzhou, Shandong, 256600, China \\ ${ }^{2}$ Shandong University of Technology, Zibo 255000, China \\ *Yin-ping CAI. Email: 461086259@qq.com
}

\begin{abstract}
Traditional Chinese medicine (TCM) is an important part of traditional medicine in China. Ecological utilization of TCM residue is a hot research topic at present. The application of antibiotic residue is a difficult point in the study of resource utilization of drug residue in China. In this paper, four batches of harmless treated oxytetraamycin residue were taken as the research object. Filtration rate, turbidity of filtrate and moisture content of filter cake were taken as the assessment indexes, and the type of filter medium and filter pressure were taken as the investigation factors. DPS software was used to process the data, so as to obtain the optimal separation conditions.
\end{abstract}

Keywords: Oxytetracycline residue, filtration rate, filtrate turbidity, filter cake moisture content, liquid-solid separation

\section{INTRODUCTION}

Traditional Chinese medicine (TCM) is an important part of Chinese traditional medicine. With the progress of modern industrial science and technology, the industrialization and scale of traditional Chinese medicine production has been deepening, and the traditional Chinese medicine industry has been developing rapidly. At the same time, the waste of medicinal residue produced in the production and processing of Chinese herbal medicine is increasing day by day. Chinese medicinal residue is generally wet material, and it is easy to corrupt if it is not disposed for a long time. It has a strange odor and causes great pollution to the surrounding environment. A large number of studies have found that the general drug residue contains cellulose, protein, sugar, calcium, magnesium, iron, phosphorus and other substances, which have high usable value. Therefore, the ecological utilization of traditional Chinese medicine residue is a hot research topic at present. The application of antibiotic residue is a difficult point in the study of resource utilization of drug residue in China.In the 1990s, there were reports of antibiotic residues being used directly as animal feed.But since 2002, China has classified antibiotic residues as "three industrial wastes" and banned their use as animal feed.In 2008, China defined antibiotic residue as hazardous waste, which needs to be recycled and treated by special departments, which is costly and a waste of resources.At present, the innocuous treatment process of oxytetracycline residue was studied, and a new innocuous treatment technology of antibiotic residue was explored. After innocuous treatment, the residue becomes a liquid-solid mixture system with larger viscosity and finer particles. In order to realize the effective utilization of the residue, liquid-solid separation is needed.

In this paper, four batches of harmless treated oxytetraamycin residue were taken as the research object. Filtration rate, turbidity of filtrate and moisture content of filter cake were taken as the assessment indexes, and the type of filter medium and filter pressure were taken as the investigation factors. DPS software was used to process the data, so as to obtain the optimal separation conditions. 
2. TEST SECTION

\subsection{Test equipment and instruments}

Table 1 Test apparatus and instruments

\begin{tabular}{|c|c|c|}
\hline Device name & model & The manufacturer \\
\hline Electronic balance & OHAUS TM & R.O.C Taiwan Co. Ltd \\
\hline Filter separation unit & / & homemade \\
\hline viscometer & NDJ-1 & Shanghai Weighing Equipment Factory \\
\hline Laser particle size meter & FrtischAnalysettle 22 & German Frtisch Company \\
\hline Digital display electric stirrer & $\mathrm{JJ}-1 \mathrm{~A}$ & $\begin{array}{l}\text { Jintan Hengfeng Instrument Manufacturing Co., } \\
\text { Ltd }\end{array}$ \\
\hline Super constant temperature tank & $\mathrm{CH} 1015$ & $\begin{array}{l}\text { Shanghai Sunny Hengping Scientific Instrument } \\
\text { Co., Ltd }\end{array}$ \\
\hline $\begin{array}{l}\text { Electric heating constant } \\
\text { temperature blast drying oven }\end{array}$ & DHG-9053A & Shanghai Yiheng Scientific Instrument Co., Ltd \\
\hline
\end{tabular}

\subsection{Test materials}

The test materials were provided by Lunan Pharmaceutical Factory. The initial temperature of the materials was $80^{\circ} \mathrm{C}$, stored in a cool place and
The devices and test instruments used in the test are shown in Table 1.

Table 2 Basic property test of oxytetracycline residue

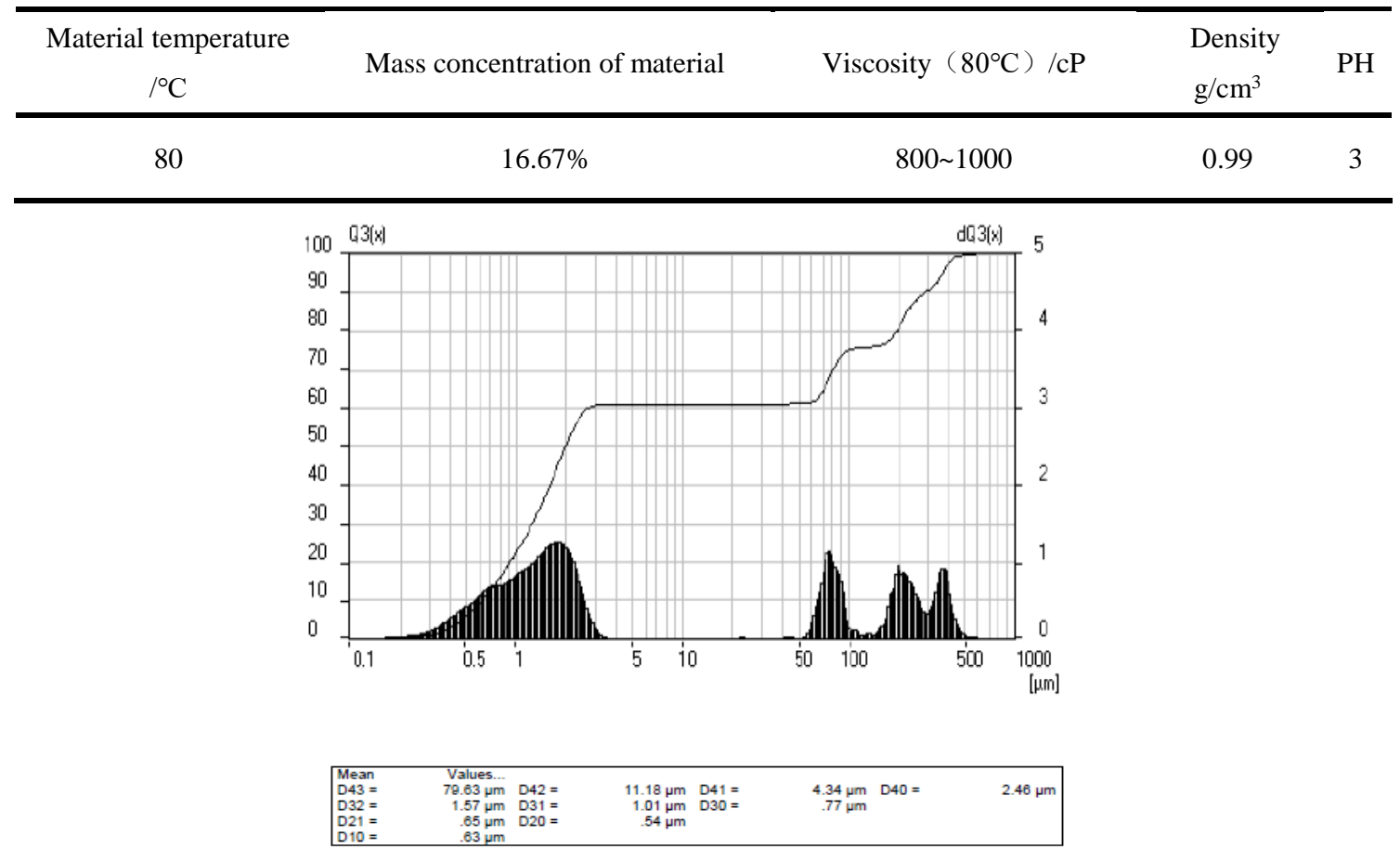

Fig. 1 Grain size distribution of oxytetracycline residue 


\subsection{Evaluation Indicators}

There are three indicators to evaluate the effect of filtration and separation, including filtration rate, turbidity of filtrate and moisture content of filter cake.Where filtration rate refers to the time required to obtain the same filtrate volume; The turbidity of filtrate can be a qualitative characterization of the content of solid particles in the filtrate. The more the number of solid particles, the greater the turbidity of filtrate, and vice versa.The moisture content of filter cake refers to the percentage of water in the filter cake. The lower the moisture content of filter cake, the better the filtration effect, and the lower the drying load at the later stage.

\section{TEST RESULTS AND DISCUSSION}

\subsection{Filter cake specific resistance and compressibility coefficient}

The specific resistance and compressibility coefficient of filter cake are important indexes to evaluate the difficulty of material filtration and separation.

In order to further optimize the operating conditions of filtration and separation, the uniform design method was adopted, and $U$ was selected $_{6}{ }^{*}\left(6^{4}\right)$. The filter rate, filtrate turbidity and filter cake moisture content were taken as the assessment indexes, the filter medium model and filter pressure were taken as the investigation factors, and DPS software was selected as the data processing method. The original test data obtained were shown in Table 3. After preliminary processing of the test data in Table 3 , the obtained results are shown in Table 4. It can be seen from the table that the average filtration rate and the moisture content of filter cake fluctuate little with the change of test conditions, while the turbidity of filtrate fluctuates greatly with the change of test conditions.

Table 3 Uniform design test data recording table

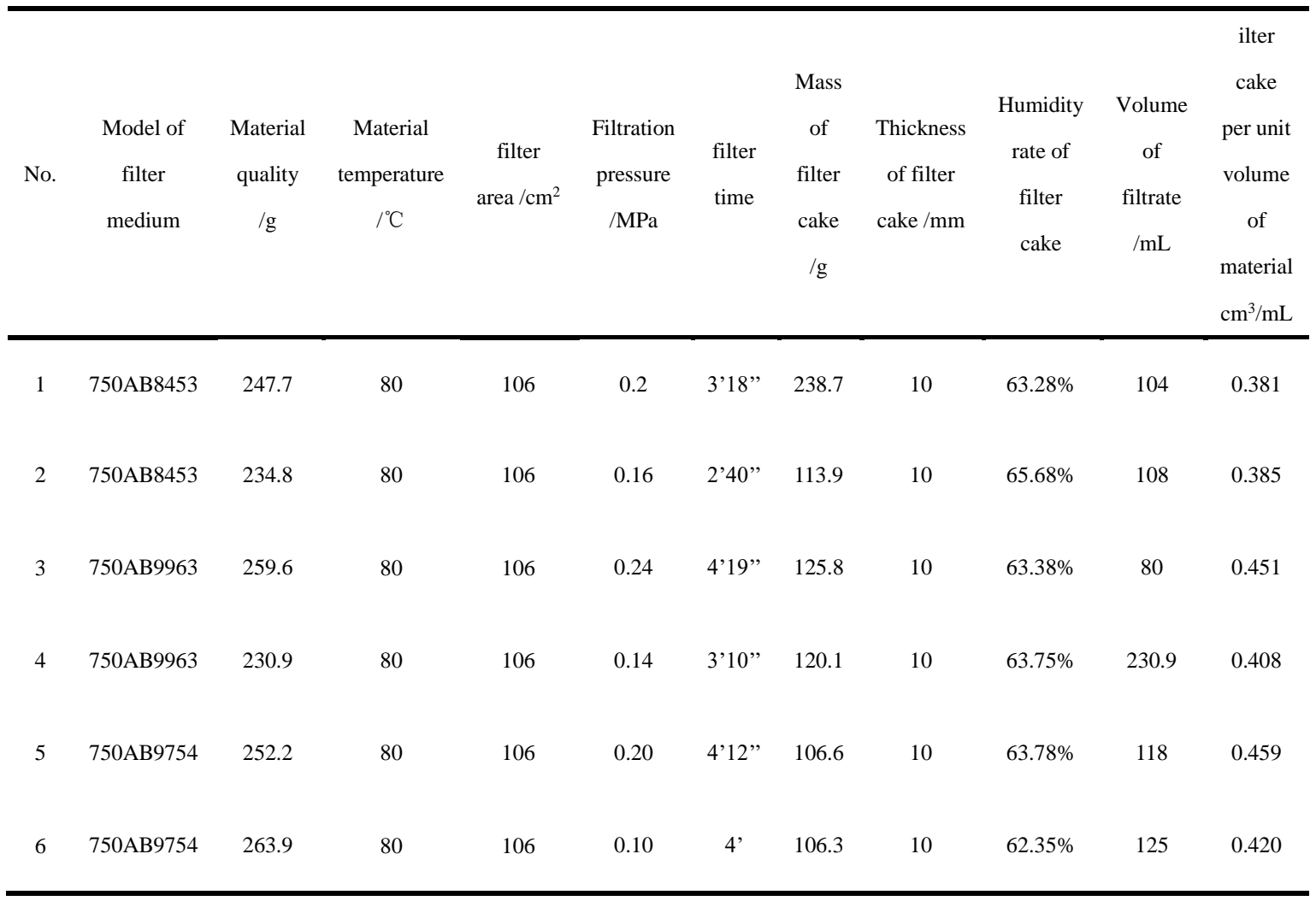


Table 4 Uniform design test results

\begin{tabular}{|c|c|c|c|c|c|}
\hline \multirow{2}{*}{$\begin{array}{l}\text { Test } \\
\text { no. }\end{array}$} & \multicolumn{2}{|c|}{ Factors affecting the } & \multicolumn{3}{|c|}{ Assessment indicators } \\
\hline & $\begin{array}{c}\text { filter } \\
\text { medium }\end{array}$ & Pressure/MPa & $\begin{array}{l}\text { Average filtration rate } \\
\qquad / \mathrm{mL} / \mathrm{s} / \mathrm{cm}^{2} / \mathrm{Y} 1\end{array}$ & $\begin{array}{l}\text { The filtrate turbidity } \\
\text { Y2 }\end{array}$ & $\begin{array}{l}\text { The moisture } \\
\text { content of filter } \\
\text { cake is } \mathrm{Y} 3\end{array}$ \\
\hline 1 & $750 \mathrm{AB} 8453$ & 0.16 & 0.00476 & 17.3 & $63.28 \%$ \\
\hline 2 & $750 \mathrm{AB} 8453$ & 0.24 & 0.00590 & 39.0 & $65.68 \%$ \\
\hline 3 & $750 \mathrm{AB} 9963$ & 0.14 & 0.00398 & 19.5 & $63.38 \%$ \\
\hline 4 & $750 \mathrm{AB} 9963$ & 0.20 & 0.00497 & 28.1 & $63.75 \%$ \\
\hline 5 & $750 \mathrm{AB} 9754$ & 0.10 & 0.00419 & 9.9 & $63.78 \%$ \\
\hline 6 & 750AB9754 & 0.18 & 0.00552 & 12.8 & $62.35 \%$ \\
\hline
\end{tabular}

The experimental results were treated by quadratic polynomial stepwise regression method. Due to the existence of multiple assessment indexes in the test, the method of membership degree is adopted to process the data. The membership degree of filtration rate, turbidity of filtrate and moisture content of filter cake is calculated. The calculation formula is as follows:

$Y_{1, j}=\frac{Y_{i}-Y_{\min }}{Y_{\max }-Y_{\min }}=\frac{Y_{i}-3.98}{5.90-3.98}=\frac{Y_{i}-3.98}{1.92}$

$Y_{2, \mathrm{j}}=\frac{Y_{\mathrm{i}}-Y_{\min }}{Y_{\max }-Y_{\min }}=\frac{Y_{\mathrm{i}}-0.0256}{0.1007-0.0256}=\frac{Y_{\mathrm{i}}-0.0256}{0.0751}$

$Y_{3, \mathrm{j}}=\frac{Y_{\mathrm{i}}-Y_{\min }}{Y_{\max }-Y_{\min }}=\frac{Y_{\mathrm{i}}-1.522}{1.6038-1.5225}=\frac{Y_{\mathrm{i}}-1.5225}{0.0813}$

According to the actual situation, the weights of filtration rate, filtrate turbidity and filter cake moisture content are $0.33,0.33$ and 0.33 respectively, so the comprehensive points are calculated as follows:

$$
Y_{\mathrm{i}}=0.33 Y_{1, \mathrm{i}}+0.33 Y_{\mathrm{z}, \mathrm{j}}+0.33 Y_{\mathrm{z}, \mathrm{j}}
$$

According to the above data processing method, the obtained results are shown in Table 5.Logical changes are made to the comprehensive score Y, namely $Y^{\prime}=\ln \left(\frac{Y}{1-Y}\right)$, and then carry out quadratic polynomial stepwise regression, and the fitting equation is as follows:

$\mathrm{Y}=6.64895610-6.351557317 * \mathrm{X}_{1} 22.380243902 *$ $\mathrm{X}_{2}+1.2092 \mathrm{X} \mathrm{X}_{1} * \mathrm{X}_{1}+13.185 \mathrm{X} \mathrm{X}_{1} * \mathrm{X}_{2}$

The significance analysis results of the equation are shown in Table 6. As can be seen from the table, the $\mathrm{P}$ value of the equation is $0.023418<0.05$, and the $\mathrm{P}$ values of various regression coefficients are all less than 0.05 . Therefore, the fitting equation has significance. 
Table 5 Calculation results of membership degree of uniform design test

\begin{tabular}{|c|c|c|c|c|c|c|c|c|c|}
\hline & & & & evaluation & ndex & & membershi & & \\
\hline $\begin{array}{l}\mathrm{N} \\
\mathrm{o}\end{array}$ & $\mathrm{X}_{1}$ & $\mathrm{X}_{2}$ & $\begin{array}{r}\mathrm{Y} 1 \\
\text { filter } \\
\text { rate }\end{array}$ & $\begin{array}{c}\text { 1/Y2 } \\
\text { filtrate } \\
\text { turbidity }\end{array}$ & $\begin{array}{c}\text { 1/Y3 } \\
\text { Filter } \\
\text { cake } \\
\text { moisture }\end{array}$ & $\begin{array}{c}\text { Y1 } \\
\text { member } \\
\text { ship }\end{array}$ & $\begin{array}{c}\text { 1/Y2 } \\
\text { membersh } \\
\text { ip }\end{array}$ & $\begin{array}{c}\text { 1/Y3 } \\
\text { membersh } \\
\text { ip }\end{array}$ & $\begin{array}{c}\text { Comprehensiv } \\
\text { e points } \mathrm{Y}\end{array}$ \\
\hline 1 & 1 & 0.16 & 4.76 & 0.0579 & 1.5803 & 0.4063 & 0.4303 & 0.7107 & 0.5106 \\
\hline 2 & 1 & 0.24 & 5.9 & 0.0256 & 1.5225 & 1.0000 & 0.0003 & 0.0004 & 0.3302 \\
\hline 3 & 2 & 0.14 & 3.98 & 0.0512 & 1.5778 & 0.0000 & 0.3408 & 0.6800 & 0.3369 \\
\hline 4 & 2 & 0.2 & 4.97 & 0.0355 & 1.5686 & 0.5156 & 0.1324 & 0.5674 & 0.4011 \\
\hline 5 & 3 & 0.1 & 4.19 & 0.1007 & 1.5679 & 0.1094 & 0.9996 & 0.5583 & 0.5502 \\
\hline 6 & 3 & 0.18 & 5.52 & 0.0783 & 1.6038 & 0.8021 & 0.7021 & 1.0006 & 0.8266 \\
\hline
\end{tabular}

Table 6 Significance analysis table of fitting equation

\begin{tabular}{|c|c|c|c|c|c|}
\hline \multirow[b]{2}{*}{ Sources of } & \multicolumn{5}{|c|}{ Analysis of variance table } \\
\hline & Sum of squares & Degrees of & The mean & The F value & $P$ values \\
\hline Return to the & 3.5996297 & 4 & 0.8999074 & 1025.2907 & 0.023418 \\
\hline residual & 0.0008777 & 1 & 0.0008777 & & \\
\hline \multirow[t]{2}{*}{ The total } & 3.6005074 & 5 & & & \\
\hline & Regression & Standard & Partial & $\mathrm{T}$ value & $\mathrm{P}$ values \\
\hline $\mathrm{X} 1$ & 6.351557 & 6.694658 & 0.999723 & 42.455258 & 0.0149923 \\
\hline $\mathrm{X} 2$ & 22.38024 & 1.281221 & 0.999346 & 27.640334 & 0.0230222 \\
\hline $\mathrm{X} 1 * \mathrm{X} 1$ & 1.2092 & 5.1509068 & 0.9997328 & 43.248923 & 0.0147173 \\
\hline $\mathrm{X} 1 * \mathrm{X} 2$ & 13.185 & 2.0706408 & 0.9996058 & 35.603666 & 0.017876 \\
\hline
\end{tabular}

The complex correlation coefficient

The coefficient of determination $\mathrm{R}^{\wedge} 2=0.999756$

Residual standard deviation

Adjust correlation coefficient $\mathrm{Ra}=0.999390$

The best point predicted by the fitting equation is: $Y^{\prime}=2.599, X 1=3, X 2=0.24$. The inverse logical transformation of $\mathrm{Y}^{\prime}$ is carried out, and the $\mathrm{Y}$ value is obtained as 0.93 . The verification test was
Adjust the determination coefficient $\mathrm{Ra}^{\wedge} 2=0.998781$ carried out under this experimental condition, and the test results are shown in Table 7, from which we can see. 
Table 7 confirmatory experimental results

\begin{tabular}{|c|c|c|c|c|c|c|c|}
\hline & $\mathrm{X}_{1}$ & $\mathrm{X}_{2}$ & $\mathrm{Y}_{1}$ & $\mathrm{Y}_{2}$ & $\mathrm{Y}_{3}$ & $\mathrm{Y}$ & error \\
\hline $\begin{array}{c}\text { Forecast } \\
\text { test }\end{array}$ & 3 & 0.24 & & & & 0.93 & \\
\hline $\begin{array}{c}\text { Validation } \\
\text { test }\end{array}$ & 3 & 0.24 & & & & & \\
\hline
\end{tabular}

\subsection{Result discussion}

We designed the method of uniform experiment, obtained the original experimental data, and used DPS software to process the data, and obtained the fitting equation with good significance. The optimal point of filtering oxytetracycline residue was determined as $\mathrm{Y}^{\prime}=2.599, \mathrm{X} 1=3, \mathrm{X} 2=0.24$. The verification test was carried out under this experimental condition, and the difference between it and the predicted value was small, indicating that the prediction effect of the fitting equation was good. This method is reliable and effective, and has certain application and popularization value.

\section{CONCLUSION}

In this paper, four batches of harmless treated oxytetraamycin residue were taken as the research object. Filtration rate, turbidity of filtrate and moisture content of filter cake were taken as the assessment indexes, and the type of filter medium and filter pressure were taken as the investigation factors. DPS software was used to process the data, so as to obtain the optimal separation conditions.

\section{REFERENCES}

[1] Guo Yidong, He Xing, Feng Xing et

al.Research progress in comprehensive utilization of Chinese medicinal residues [J]. Journal of Chengdu University, 2015,34 (2):125 $\sim 128$

[2] Sun Hongli, Liu Zhiqin, Wang Jun et al. Method of Removing Active Components from
Oxytetracycline Residues [J].Journal of Hebei University, 2009,06 (2):23 25

[3] Yang Junqi, Yang Yinghua, Study on Application of Alkali Treated Otetracycline Residue in Egg Quail Diet [J].Animal Husbandry and Veterinary Medicine of Hebei Province. 1996,12 (4):176 177

[4] Chinese Veterinary Drug Commission. Veterinary Drug Code of the People's Republic of China [S]. Beijing: Agricultural Press, 1990:568 570

[5] H. Li, P. Xu, et. al., Low-voltage and fast-response $\mathrm{SnO} 2$ nanotubes/perovskite heterostructure photodetector, Nanotechnology, 32(2021)375202.

[6] Wang, Y., Wang, W., Yang, X., et. al., ITGA8 positive cells in the conventional outflow tissue exhibit Schlemm's canal endothelial cell properties, Life Sciences, 278(2021)119564.

[7] P. Xu, J. Cao, et. al., Quantum chemical study on the adsorption of megazol drug on the pristine $\mathrm{BC} 3$ nanosheet, Supramolecular Chemistry, 33(2021)63-69.

[8] P. Xu, , C. Geng, et. al., Application of Boron-doped Graphdiyne (BGDY) in Dehydrogenation of Benzyl Alcohol to Benzaldehyde, Basic \& Clinical Pharmacology \& Toxicology, 128SI3(2021)97-98. 